\title{
Prolonged Fever and Lymphadenopathy in a Series of Egyptian Patients: The Etiology Based on Histopathological Examination
}

\author{
Moussa Mohamed, Fatma Rageh ${ }^{\mathbf{1}}$, Abd El Gwad, Walaa ${ }^{2}$ \\ ${ }^{1}$ Department of Infectious, Gastrointestinal and Hepatology Diseases, Faculty of \\ Medicine, Suez University, Egypt. \\ ${ }^{2}$ Department of Pathology, Faculty of Medicine, Suez University, Egypt.
}

Corresponding Author Moussa Mohamed, Fatma Rageh

Mobile:

$+201126319318$

E mail:

frageh2002@hotmail. com

Key words: prolonged fever; lymphadenopathy; malignancy; reactive hyperplasia; infections
Introduction and study aim: prolonged fever and lymphadenopathy (LAP) are two interrelating features that constitute a diagnostic challenge in medical practice. With the great variety in differential diagnoses, a wise clinical impression is needed to reach a provisional diagnosis. This is achieved through knowledge and awareness of the prevalent etiologies among our population.

Patients and methods: We included 269 patients with prolonged fever and lymphadenopathy to have an excisional biopsy to reach a definitive diagnosis via histopathological examination. In addition, laboratory tests were performed to assess the role of serology to predict probable diagnoses.

Results: Three main etiologies of prolonged fever and lymphadenopathy were detected; malignancy (41.7\%), followed by non-specific changes

\section{INTRODUCTION}

Lymph nodes of abnormal size, number, and consistency are known as lymphadenopathy (LAP). Usually, some lymph nodes have different sizes based on their site, and the individual's age. Evaluation of a case with lymphadenopathy is challenging because of the extensive related differential diagnoses and their diversity among different regions. Thus, for making a provisional diagnosis, it is crucial to have familiarity with the etiologic pattern of lymphadenopathy in a given geographical area [1].

Among the developed countries, LAP is mainly attributed to infectious etiologies including upper respiratory tract infections, cytomegalovirus, and (reactive hyperplasia) (30.5\%), then infections $(27.8 \%)$. The most commonly involved lymph nodes were cervical and axillary, then inguinal. More than half of the patients had only fever and lymphadenopathy, while cachexia and anorexia were the most common associated presentations among others. Most of the patients had high ESR level, whereas high LDH and CRP levels presented in nearly $34 \%$ and $22 \%$ of them respectively. High CRP, eosinophilia and elevated LDH, characterized malignancy whilst infection was commonly associated with lymphocytosis, monocytosis and high ESR. Old age and high ESR were significant independent predictors of malignancy, and lymphocytosis was a significant predictor of infection.

Conclusion: In our region, malignancy is the commonest etiology for fever and lymphadenopathy, in addition to reactive hyperplasia and infections, respectively.

Epstein-Barr Virus. While in countries with low socioeconomic status, tuberculosis (TB), toxoplasmosis, leishmaniasis, HIV, and fungi are predominate causes. Nevertheless, a vast majority of the causes is non-specific reactive LAP [2], nevertheless, prevalence of malignancy does not correlate to geography.

Usually, history taking and clinical examination are sufficient to establish a diagnosis; however, some cases would require further investigations to determine the etiology. In atypical conditions, laboratory examinations, imaging, and tissue biopsy are mandatory. Imaging, such as ultrasound and Computed tomography (CT), can detect the size and 
distribution of the node precisely. Whilst, tissue biopsy by fine needle aspiration biopsy (FNAC) or excisional biopsy is the gold standard evaluation for LAP [3].

When lymphadenopathy is accompanied by prolonged fever, it needs vigorous investigations to reach the diagnosis. Prolonged fever is defined as fever $\geq 38.3^{\circ} \mathrm{C}$ for $>2$ weeks" [4]. Similar to LAP, detection of the etiology of prolonged fever is challenging as well. Thus, in this study, we aimed at identification of different etiologies of prolonged fever and lymphadenopathy in our region.

\section{SUBJECTS AND METHODS}

A cross section study was carried out at Kafer El Sheik General Hospital. After obtaining the institutional review board approval, we collected patients' data from the hospital's medical records during the period from January 2016 up to December 2019. The study included 269 patients with prolonged fever and lymphadenopathy, who were subjected to excisional biopsy. Prolonged fever was defined as fever $\geq 38.3^{\circ} \mathrm{C}$ for $>2$ weeks, and lymphadenopathy denoted lymph nodes of abnormal size, consistency, and number. The collected data included medical history, physical findings, laboratory results, and histopathological examination report. Laboratory data included complete blood count (CBC) with differential, Erythrocyte Sedimentation Rate (ESR), Lactate Dehydrogenase (LDH) and C reactive protein (CRP). All specimens were excisional biopsy of the whole node or multiple nodes. Histopathological examination was performed using $\mathrm{H}$ and $\mathrm{E}$ staining. Histopathological findings were categorized into the following diagnoses: malignancy, infection, and unspecified. Statistical analysis was done using SPSS version 20. A p value of less than 0.05 was considered significant.

\section{RESULTS}

In this study, we included 269 patients who had prolonged fever and lymphadenopathy. The most common cause for prolonged fever and lymphadenopathy was malignancy $(112 ; 41.7 \%)$, followed by non-specific changes (reactive hyperplasia) $(82 ; 30.5 \%)$, then infections $(75 ; 27.8 \%)$ (Table 1). When patients' features were compared based on their pathological diagnosis, we found that old age was characteristic of malignancy, while there was no gender gender-predominance among different diagnoses (Table 2).

The majority of patients had localized lymphadenopathy, with the cervical lymph nodes are commonly affected. The most prevalent sites of lymphadenopathies were cervical, axillary, and inguinal lymph nodes. Axillary and inguinal lymphadenopathies were more common among malignancy cases, while cervical lymphadenopathies dominated among nonspecific pathology (Table 3). Nearly $63 \%$ of patients were asymptomatic. The most common presentation among cases with malignancy was cachexia and anorexia, while cough and expectoration, followed by weight loss were characteristic of infection. The least common symptom was malaise and it was solely associated with nonspecific pathology (Table 4).

Only $56 \%$ of the patients expressed positive serology. The majority of patients had elevated ESR. Approximately one third of the patients had elevated $\mathrm{LDH}$, and elevated CRP was found among one fifth of them. CBC with differential revealed a predominance of lymphocytosis. Of notice, lymphocytosis, and elevated ESR were more common among cases with infection. Monocytosis was only evident among cases with infection, while CRP was higher among malignant cases. In addition, eosinophilia and elevated LDH were solely found among cases with malignancy (Table 5).

In univariate and multivariate analysis, we found that increasing age $(\mathrm{OR}=1.06,95 \% \mathrm{CI}=1.04-$ 1.08) and high ESR (OR=0.16, 95\% CI $=0.06-$ 0.42 ) were significant independent predictors of malignancy, and lymphocytosis was a significant predictor of infection $(\mathrm{OR}=1.99,95 \% \mathrm{CI}=1.04$ 3.83). 
Table (1): Distribution of different pathological diagnoses.

\begin{tabular}{|l|c|}
\hline \multicolumn{1}{|c|}{ Pathological diagnosis } & $\mathbf{N}(\boldsymbol{\%})$ \\
\hline Malignancy & $\mathbf{1 1 2}(\mathbf{4 1 . 6})$ \\
Non Hodgkin lymphoma & $62(23)$ \\
B cell lymphoma & $60(96.7)$ \\
T cell lymphoma & $2(3.3)$ \\
Hodgkin lymphoma & $33(12.3)$ \\
Mixed cellularity & $22(70)$ \\
Nodular sclerosis & $10(30)$ \\
Metastatic & $17(6.3)$ \\
\hline Infections & $\mathbf{7 5 ( 2 7 . 8 )}$ \\
Viral & $35(13)$ \\
Bacterial & $36(13.3)$ \\
Tuberculosis & $19(7.1)$ \\
Others & $17(6.2)$ \\
Parasitic & $4(1.5)$ \\
Toxoplasmosis & $4(1.5)$ \\
\hline Nonspecific changes (Reactive hyperplasia) & $\mathbf{8 2 ( 3 0 . 6 )}$ \\
\hline \multicolumn{2}{|c|}{} \\
\hline
\end{tabular}

Table (2): Association between patients' characteristics and pathological diagnoses.

\begin{tabular}{|c|c|c|c|c|c|}
\hline & & & ogical Diagn & & \\
\hline Patients' characteristics & $\begin{array}{c}\text { Total } \\
\mathrm{n}=269(\%)\end{array}$ & $\begin{array}{l}\text { Malignancy } \\
\mathrm{n}=\mathbf{1 1 2}(\%)\end{array}$ & $\begin{array}{c}\text { Infection } \\
\mathrm{n}=75(\%)\end{array}$ & $\begin{array}{l}\text { Nonspecific } \\
\mathbf{n}=82(\%)\end{array}$ & $\mathbf{P}$ \\
\hline $\begin{array}{l}\text { Sex } \\
\quad \text { Male } \\
\text { Female }\end{array}$ & $\begin{array}{l}148(55) \\
121(45)\end{array}$ & $\begin{array}{l}65(58) \\
47(42)\end{array}$ & $\begin{array}{l}40(53.3) \\
35(46.7)\end{array}$ & $\begin{array}{l}43(52.4) \\
39(47.6)\end{array}$ & 0.698 \\
\hline $\begin{array}{l}\text { Age }(\text { years }) \\
\quad \text { Mean } \pm \text { SD. } \\
\text { Median (Min. }- \text { Max.) }\end{array}$ & $\begin{array}{l}32.7 \pm 21.6 \\
28(1-85)\end{array}$ & $\begin{array}{c}45.5 \pm 20 \\
49.5(2-85)\end{array}$ & $\begin{array}{c}23.5 \pm 17 \\
20(1-70)\end{array}$ & $\begin{array}{c}23.7 \pm 18.3 \\
19(1-75)\end{array}$ & $<0.001^{*}$ \\
\hline
\end{tabular}

Table (3): Association between lymph nodes' site and distribution of LAP, and pathological diagnoses

\begin{tabular}{|c|c|c|c|c|c|}
\hline & & \multicolumn{3}{|c|}{ Pathological Diagnosis } & \multirow[b]{2}{*}{$\mathbf{P}$} \\
\hline Lymph nodes & $\begin{array}{c}\text { Total } \\
\mathrm{n}=\mathbf{2 6 9}(\%)\end{array}$ & $\begin{array}{l}\text { Malignancy } \\
\mathrm{n}=112(\%)\end{array}$ & $\begin{array}{c}\text { Infection } \\
\mathrm{n}=75(\%)\end{array}$ & $\begin{array}{l}\text { Nonspecific } \\
n=82(\%)\end{array}$ & \\
\hline $\begin{array}{l}\text { Clinical } \\
\text { Localized } \\
\text { Generalized }\end{array}$ & $\begin{array}{c}265(98.5) \\
4(1.5)\end{array}$ & $\begin{array}{c}109(97.3) \\
3(2.7)\end{array}$ & $\begin{array}{c}74(98.7) \\
1(1.3) \\
\end{array}$ & $\begin{array}{c}82(100) \\
0(0)\end{array}$ & 0.308 \\
\hline $\begin{array}{l}\text { Anatomical Site } \\
\text { Cervical } \\
\text { Axillary } \\
\text { Inguinal } \\
\text { Submandibular } \\
\text { Mesentric } \\
\text { Submental } \\
\text { Supraclavicular } \\
\text { Paraaortic } \\
\text { Occipital }\end{array}$ & $\begin{array}{c}148(55) \\
60(22.3) \\
36(13.4) \\
8(3) \\
7(2.6) \\
5(1.9) \\
5(1.9) \\
2(0.7) \\
1(0.4)\end{array}$ & $\begin{array}{c}51(45) \\
35(31.2) \\
21(18.8) \\
3(2) \\
0(0) \\
0(0) \\
3(2) \\
2(1) \\
0(0)\end{array}$ & $\begin{array}{c}47(62.7) \\
14(18.7) \\
8(10.7) \\
2(2.7) \\
1(1.3) \\
1(1.3) \\
1(1.3) \\
0(0) \\
1(1.3)\end{array}$ & $\begin{array}{c}50(61) \\
11(13.4) \\
7(8.5) \\
3(3.7) \\
6(7.3) \\
4(4.9) \\
1(1.2) \\
0(0) \\
0(0)\end{array}$ & $\begin{array}{l}0.030^{*} \\
0.009^{*} \\
0.085 \\
0.908 \\
0.003^{*} \\
0.027^{*} \\
0.741 \\
0.518 \\
0.270\end{array}$ \\
\hline
\end{tabular}


Table (4): Association between clinical presentation and pathological diagnosies.

\begin{tabular}{|l|c|c|c|c|c|}
\hline & & \multicolumn{3}{|c|}{ Pathological Diagnosis } & \multirow{2}{*}{ P } \\
\cline { 1 - 5 } Associated clinical symptoms & $\begin{array}{c}\text { Total } \\
\mathbf{n = 2 6 9}(\%)\end{array}$ & $\begin{array}{c}\text { Malignant } \\
\mathbf{n = 1 1 2}(\boldsymbol{\%})\end{array}$ & $\begin{array}{c}\text { Infection } \\
\mathbf{n = 7 5}(\boldsymbol{\%})\end{array}$ & $\begin{array}{c}\text { Nonspecific } \\
\mathbf{n = ~ 8 2}(\boldsymbol{\%})\end{array}$ & \\
\hline & & & & & \\
None & $170(63.2)$ & - & - & - & \\
Wight loss & $47(17.5)$ & $25(22.3)$ & $22(29.3)$ & $0(0)$ & $<0.001^{*}$ \\
Cough and expectoration & $26(9.7)$ & $0(0)$ & $26(34.7)$ & $0(0)$ & $<0.001^{*}$ \\
Cashexia and anorexia & $22(8.2)$ & $22(19.6)$ & $0(0)$ & $0(0)$ & $<0.001^{*}$ \\
Malaise & $4(1.5)$ & $0(0)$ & $0(0)$ & $4(4.9)$ & $0.016^{*}$ \\
\hline
\end{tabular}

Table (5): Association between patients' serology and pathological diagnoses.

\begin{tabular}{|c|c|c|c|c|c|}
\hline \multirow[b]{2}{*}{ Serology } & \multirow[b]{2}{*}{$\begin{array}{c}\text { Total } \\
n=269(\%)\end{array}$} & \multicolumn{3}{|c|}{ Pathological Diagnosis } & \multirow[b]{2}{*}{$\mathbf{P}$} \\
\hline & & $\begin{array}{c}\text { Malignant } \\
n=112(\%) \\
\end{array}$ & $\begin{array}{c}\text { Infection } \\
\mathrm{n}=75(\%)\end{array}$ & $\begin{array}{l}\text { Nonspecific } \\
\mathbf{n}=82(\%)\end{array}$ & \\
\hline Negative & 118 (43.9) & $56(47.5)$ & $5(4)$ & $57(48.5)$ & $<0 \Omega 01^{*}$ \\
\hline Positive & $151(56.1)$ & $56(37)$ & $70(46.5)$ & $25(16.5)$ & $<0.001$ \\
\hline Lymphocytosis & $60(39.7)$ & $0(0)$ & $35(58.3)$ & $25(41.7)$ & $<0.001^{*}$ \\
\hline Eosinophilia & $24(15.9)$ & $24(100)$ & $0(0)$ & $0(0)$ & $<0.001^{*}$ \\
\hline Leukocytosis & $67(44.4)$ & $32(47.7)$ & $35(52.3)$ & $0(0)$ & $<0.001^{*}$ \\
\hline Monocytosis & $30(19.9)$ & $0(0)$ & $30(100)$ & $0(0)$ & $<0.001^{*}$ \\
\hline Elevated ESR & $118(78.1)$ & $51(43.2)$ & $67(56.3)$ & $0(0)$ & $<0.001^{*}$ \\
\hline Elevated LDH & $51(33.8)$ & $51(100)$ & $0(0)$ & $0(0)$ & $<0.001^{*}$ \\
\hline Elevated CRP & 33 (21.9) & $17(51.5)$ & $16(48.5)$ & $0(0)$ & $<0.001^{*}$ \\
\hline
\end{tabular}

\section{DISCUSSION}

Among the examined biopsies, three main common etiologies of combined LAP and prolonged fever were identified; malignancy $(41.6 \%)$, reactive hyperplasia $(30.6 \%)$ and infections $(27.8 \%)$. Among malignancy cases, NHL was the most common, whereas among infectious causes, viral infections predominated followed by TB.

Multiple studies augment these findings. For instance, Özkan et al found similar pattern among the Turkish population, malignancy was the most common etiology for LAP (66.5\%), followed by reactive hyperplasia $(21.5 \%)$, and granulomatous diseases $(11.2 \%)$. Similar to our study, NHL was the most common malignancy followed by HL, then metastatic cancer, but with a relatively higher incidence than in our study [3]. In an Indian study, Roy et al reported a similar pattern as well where lymphomas affected $44.5 \%$ of all cases with LAP, followed by reactive hyperplasia $(21.6 \%)$, then tuberculous lymphadenitis (18\%) and metastatic nodes $(8.5 \%)$ [5]. Similarly, Olu-eddo reported that malignancy was the most common cause of LAP among Nigerian population (48.5\%), followed by TB (35\%), then non-specific changes $(15.6 \%)$ [6].

This contrasts Kirwan et al findings where they found that, among inhabitants of Peru, TB was the most common histopathological diagnosis (34\%) followed by hyperplasia (27\%), and lymphoma (13\%) [2]. The same was reported by Biswas et al in an another Indian study, where TB represented approximately $45 \%$ of cases presented with cervical LAP, followed by nonspecific changes (20\%) [7]. Similar to the latter two studies, Ismail and Muhammed found the same pattern among Pakistani participants [8].

It is important to mention that two main factors contribute to the diversity of diagnoses; geographical distribution, and the studied age group. For instance, participants from developed countries tend to have a higher probability of non-infectious causes of LAP, in contrast to developing countries where infections predominate [9]. Moreover, the rate of malignancy detection was higher when extremities of age, especially old age groups, were included. In contrast to the opposing studies, we included a wide range of age groups including the extreme age groups (1-85), which raised the chance for malignancy detection. 
We noticed that recent studies less frequently report high incidence of TB. In the past, TB used to be endemic in some countries; nonetheless, with the advanced treatment that rate became limited.

Among all cases, we found that the most common site for LAP was cervical, followed by axillary, then inguinal LNs. Most of the studies in the literature support this finding ${ }^{[3,10]}$. It is believed that peripheral LNs, especially those in the upper half of the body are more accessible, easily biopsied, and provide more reliable diagnoses than those of the lower half of the body. While cervical and axillary LAP depict more specific diagnosis, inguinal, popliteal and femoral represent non-specific variations, chronic inflammation or fibrotic changes [5].

Interestingly, more than $60 \%$ of patients presented with LAP and fever only; otherwise, weight loss was the most common associated presentation. This corresponds to the higher incidence of malignancy among our cases, as weight loss is more common with lymphoma than with other causes. On the other hand, common constitutional manifestations were less common, which match well with infectious diseases [11]. Results from Kirwan et al and Cunha et al augment ours; they stated that patients with LAP and fever, and was diagnosed with malignancy had significant weight loss. While, in the same studies, constitutional manifestations were the least common presenting clinical features, which correspond to infectious causes of LAP and fever [2,12].

We found that malignancy features included eosinophilia, high CRP and $\mathrm{LDH}$, while infections were characterized by lymphocytosis, monocytosis and elevated ESR. Predictors of malignancy included old age and high ESR, and those of infections included lymphocytosis. Kadah et al agree with us, they declared that the majority of patients with cervical LAP had high LDH and CRP levels, which were consistent with malignancy. They also reported that old age was correlated with malignancy occurrence with a 1.037 increase in malignancy odds per 10-year increase in age [13]. Additionally, Cunha et al augmented our findings as well, as they reported that high LDH and eosinophilia levels were associated with lymphoma and preleukemia. Nonetheless, high ESR was found to be associated with infections, especially TB $[8,14$, 12].

\section{CONCLUSION}

We concluded that malignancy was the most common etiology of combined LAP and prolonged fever in our region. NHL was the most common malignancy of the examined cases. We opine that increase in life expectancy among our population produced that high prevalence of malignancy; fortunately, this prevalence is lower than in other countries. The same applies for the incidence of some infectious agents including TB, unlike other endemic countries, which proved to have higher figures. Noticeably, infectious causes still an inevitable etiology that affects a considerable number of patients. Apart from LAP and fever, some personal, clinical, and serological features can predicts specific diagnoses including increased age, weight loss, high ESR, and lymphocytosis.

To the best of our knowledge, scarce number of studies included these specific study inclusion criteria including the diagnosis (combined LAP and fever), and the wide range of age groups, and the relatively large sample size. Furthermore, thorough history taking and examination were considered to assess clinical predictors. We also chose reliable diagnostic methods such as excisional biopsy besides serological markers. The study was limited by location, as only one hospital was included. We recommend conduction of further multicentric studies to accurately illustrate the geographical distribution of causes of combined LAP and prolonged fever.

\section{Conflict of interest: None}

Financial disclosure: None

Ethical consideration: the study approved by the local institutional review board

Contributors: study design, writing, data entry, and analysis were conducted by Fatma Rageh Moussa, and data collection and entry was handled by Walaa Abd El Gawad.

\section{REFERENCES}

1. Mohseni S. Peripheral Lymphadenopathy: Approach and Diagnostic Tools. Iran J Med Sci. 2014; 39 (2):158-170. 
2. Kirwan DE, Ugarte-gil C, Gilman RH, Syed M. Hasan Rizvi, Gustavo Cerrillo, Jaime Cok, et al. Histological Examination in Obtaining a Diagnosis in Patients with Lymphadenopathy in Lima, Peru. Am. J. Trop. Med. Hyg. 2017; 97(4):1271-1276.

3. Özkan EA, Göret CC, Özdemir ZT, Yanık S, Göret NE. Evaluation of peripheral lymphadenopathy with excisional biopsy: sixyear experience. Int J Clin Exp Pathol. 2015; 8(11):15234-15239.

4. Petersdorf RG BP. Fever of unexplained origin: report on 100 cases. Medicine (Baltimore). 1961; 40(1).

5. Roy A, Kar R, Basu D, Badhe BA. Spectrum of histopathologic diagnosis of lymph node biopsies: A descriptive study from a tertiary care center in South India over 51/2 years. Indian J Pathol Microbiol 2013; 56:103-108.

6. Adesuwa Noma Olu-eddo CEO. Diagnostic evaluation of primary cervical adenopathies in a developing country Adesuwa. Pan African Medical Journal. 2011;10(52):1-7.

7. Biswas G, Das A, Haldar D. ClinicoPathological Correlates of Cervical Lymphadenopathy: A Hospital Based Study. Indian J Otolaryngol Head Neck Surg. 2013; 65(7):42-47.

8. Ismail M, Muhammad M. Frequency of tuberculosis in cervical. J Postgrad Med Inst. 2013; 27(3):342-6.
9. Behera S, Subrahmanyam DKS, Bajpai J, Pradhan A, Singh A. Clinical and etiological spectrum of prolonged fever and special reference to $\mathrm{HIV}$ patients at a tertiary care centre. Int J Res Med Sci. 2018;6(7):1-8.

10. Reddy DL, Daniel W, Venter F, Pather S. Patterns of Lymph Node Pathology; Fine Needle Aspiration Biopsy as an Evaluation Tool for Lymphadenopathy: A Retrospective Descriptive Study Conducted at the Largest Hospital in Africa. PLOS ONE. 2015;10(6):1-10.

11. Gaddey HL, Riegel AM. Evaluation of Unexplained Lymphadenopathy. American Family Physician. 2016;94(11):896-903.

12. Cunha BA, Lortholary O, Cunha CB. Fever of Unknown Origin: A Clinical Approach. Am J Med. 2015;128(10):1138.e1-e1138.e15.

13. Kadah B Al, Popov HH, Schick B, Knobber D. Cervical lymphadenopathy: study of 251 patients. Eur Arch Otorhinolaryngol. 2015; 272:745-752.

14. Park JE, Ryu YJ, Kim JY, Kim YH, Park JY, Lee $\mathrm{H}$, et al. Cervical lymphadenopathy in children : a diagnostic tree analysis model based on ultrasonographic and clinical findings. [published online a head of print. Eur Radio. 2020;10.1007/s00330-020-06794-w.. 